\title{
Confirmation of a Major QTL Influencing Oral Morphine Intake in C57 and DBA Mice Using Reciprocal Congenic Strains
}

\author{
Thomas N Ferraro*,', Gregory T Golden 1,2, George G Smith',2, James F Martin ${ }^{1,2}$, Candice L Schwebel', \\ Glenn A Doyle', Russell J Buono' and Wade H Berrettini' \\ 'Department of Psychiatry, Center for Neurobiology and Behavior, University of Pennsylvania, Philadelphia, PA, USA; '2Department of Veteran's \\ Affairs Medical Center, Coatesville, PA, USA
}

\begin{abstract}
C57BL/6 (B6) and DBA/2 (D2) mice exhibit disparate behavior when tested for voluntary morphine intake in a two-bottle choice drinking paradigm with B6 mice consuming 10 times more drug than D2 mice. Previous genetic mapping studies identified a locus, Mop2, on the proximal part of chromosome 10 that explained over half of the genetic variance in this mouse model of opioid selfadministration. We constructed a set of reciprocal congenic strains between B6 and D2 mice in which the proximal portion of chromosome 10 has been introgressed from one strain onto the background of the other. We tested mice from this pair of reciprocal strains together with progenitor B6 and D2 mice in a two-bottle choice drinking paradigm with morphine and quinine. The results showed that introgression of chromosome 10 alleles from the B6 strain onto a D2 genetic background increased voluntary morphine intake four-fold compared to progenitor D2 mice. Preference for morphine was also increased significantly in D2.B6-Mop2 mice compared to progenitor D2 mice. Conversely, introgression of chromosome 10 alleles from the D2 strain onto a B6 genetic background decreased morphine intake by half compared to progenitor B6 mice in B6.D2 -Mop2 mice; however, high morphine preference was maintained in this congenic strain most likely due to strong quinine aversion. When quinine was eliminated from the control bottle, morphine preference in B6.D2-Mop2 mice was decreased significantly relative to B6 and D2.B6-Mop2 mice. Overall, these data confirm the existence of a gene(s) on chromosome 10 proximal to D IOMit 124 that has a strong influence on the difference in morphine drinking behavior between B6 and D2 mice.

Neuropsychopharmacology (2005) 30, 742-746, advance online publication, 27 October 2004; doi: I0.1038/sj.npp. I 300592
\end{abstract}

Keywords: mice; complex trait; QTL; morphine; quinine; preference; consumption; opioids

\section{INTRODUCTION}

Compared to other inbred strains, C57BL/6 (B6) mice voluntarily drink large quantities of sweetened morphine solutions (Horowitz et al, 1977; Belknap et al, 1993). Oral morphine intake by B6 mice is attenuated following treatment with opioid antagonists (Berrettini et al, 1994a) suggesting that consumption of morphine solutions elicits opioid receptor-mediated phenomena in the brain. Quantitative trait locus (QTL) mapping studies indicate that a locus on the proximal end of chromosome 10 called Mop2 harbors a gene(s) that determines a large part of the

* Correspondence: TN Ferraro, Department of Psychiatry, Center for Neurobiology and Behavior, University of Pennsylvania, 415, Curie Blvd, Philadelphia, PA 19104-6I40, USA, Tel: + I 215573 4581,

Fax: + I 215573 204I, E-mail: tnf@mail.med.upenn.edu

Received 22 March 2004; revised 16 August 2004; accepted 15 September 2004

Online publication: 22 September 2004 at http://www.acnp.org/citations/ Npp092004040 138/default.pdf difference in voluntary oral morphine consumption between B6 and DBA/2 (D2) mice (Berrettini et al, 1994b). The gene encoding the $\mathrm{Mu}$ opioid receptor $(\mathrm{Oprm})$ is located on proximal chromosome 10 (Kozak et al, 1994; Giros et al, 1995) and is a compelling candidate for the Mop2 QTL; however, the causative genetic variation between B6 and D2 mice has yet to be determined.

Although advances in technology and methodology have increased the potential for identifying genes that underlie specific QTLs (Abiola et al, 2003), many obstacles hinder success. Congenic strains have proven utility for helping to elucidate the functional effects of defined segments of the genome and recent work has documented success of this approach for dissecting genetic influences on drug abuserelated phenotypes in mice (Bennett et al, 2002). Once a QTL is captured in a congenic strain, simple breeding methods can be used to further refine its position (Ferraro et al, 2004). In some cases, genomic QTL intervals introgressed in congenic strains may be resolved into multiple genetic effects that are too weak to track 
individually (Legare et al, 2000; Legare and Frankel, 2000). In the present study, we report the creation of congenic strains of mice to confirm and further elucidate the effect of a gene(s) on proximal chromosome 10 that influences voluntary morphine intake. The results confirm a strong effect of the Mop2 locus on both oral morphine consumption and preference and localize it to the proximal end of chromosome 10 between the acromere and D10Mit124.

\section{METHODS}

\section{Animals}

Mice utilized in these studies were derived from C57BL/6 (B6) and DBA/2 (D2) mice that are maintained routinely in our animal colony at the Department of Veteran's Affairs Medical Center in Coatesville, PA. Genetic drift in these inbred strains is minimized by supplementing breeders with animals purchased from the Jackson Laboratory (Bar Harbor, ME) several times per year. In general, mice are weaned at 3 weeks of age and group-housed by gender until utilized for experimentation. They are maintained on a $12 \mathrm{~h}$ light/dark schedule (lights on at 0700) and have free access to food. Water is also available ad libitum except as noted below during the two-bottle choice paradigm. All studies were approved by the Animal Care and Use Committees governing the participating laboratories.

\section{Mop2 Congenic Strains}

The reciprocal pair of congenic strains used for these experiments was created in our animal colony over the past 5 years. We followed a conventional protocol (Flaherty, 1981) that began with a $\mathrm{B} 6 \times \mathrm{D} 2$ intercross followed by backcross of the resulting F1 generation progeny to both parental strains. Backcross breeding was accomplished using a design in which both F1 males and females were mated with progenitor mice. We genotyped N2 backcross progeny using DNA extracted from tail snips acquired at the time of weaning and selected mice for subsequent rounds of backcross breeding based upon heterozygosity at a specific set of microsatellite DNA markers (Figure 1). A total of 10 serial backcross generations were produced in a reciprocal

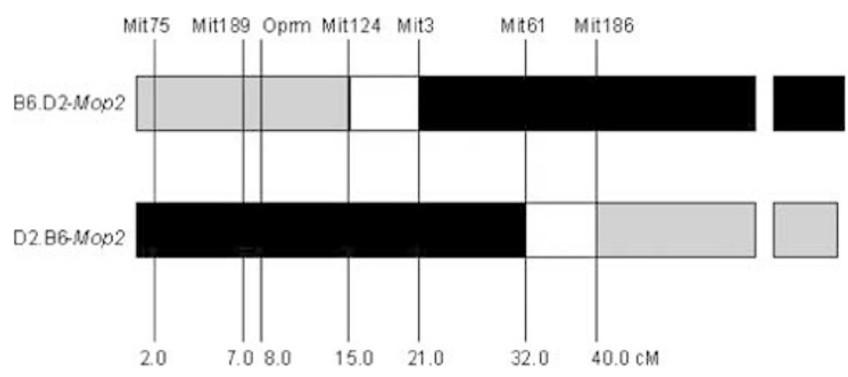

Figure I Schematic diagram of chromosome 10 in B6.D2-Mop2 (top) and D2.B6-Mop2 (bottom) congenic mice. Lightly shaded regions reflect genomic contribution from the D2 strain and darkly shaded regions reflect genomic contribution from the B6 strain. White segments represent intervals of undetermined origin. DNA microsatellite markers used for genomic introgression are shown above the chromosomes. Numbers below represent the genetic map position (http://www.informatics.jax.org/) and are given in $\mathrm{CM}$. manner. During creation of the strains, morphine consumption and preference were assessed in heterozygous congenic mice at generations N4 and N7 to insure capture of phenotypic effects. Initially, both of the reciprocal strains were developed using the marker panel spanning the interval between D10Mit75 and D10Mit186; however, a very small number of B6.D2-Mop2 strain progeny were obtained at generation $\mathrm{N} 8$ and as a result it was not possible to identify a sufficient number of pups that inherited the entire introgression panel. The development of the B6.D2-Mop2 strain then proceeded through the N9 and N10 generations using a smaller region of introgression defined by D10Mit75 proximally and D10Mit124 distally (Figure 1). At generation N10, heterozygous mice were intercrossed and DNA from N10F1 progeny was analyzed to identify homozygous congenic mice. Homozygous mice were brother $\times$ sister mated to propagate each of the reciprocal strains. B6.D2Mop2 N10F5-F7 and D2.B6-Mop2 N10F10-F12 mice were used in morphine $v s$ quinine experiments. B6.D2-Mop2 N10F5-F9 and D2.B6-Mop2 N10F10-F14 mice were used in morphine $v s$ saccharin experiments.

\section{Genotyping}

DNA microsatellite markers were analyzed using PCR amplification followed by electrophoresis on polyacrylamide (Berrettini et al, 1994b) or agarose gels (Ferraro et al, 1998) as described previously. A B6/D2 strain polymorphism in the Oprm gene was typed as follows: approximately $100 \mathrm{ng}$ of tail DNA was used in a PCR reaction with primers that amplified a $360 \mathrm{bp}$ amplicon containing exon 10 of the Oprm gene. The PCR conditions were $1 \times$ standard Perkin Elmer PCR buffer containing $125 \mu \mathrm{M}$ dNTPs, $0.1 \mathrm{pmol} / \mu \mathrm{l}$ forward primer (5'-GGTTATGCCTCTCTGGAT TAG- $\left.3^{\prime}\right), 0.1 \mathrm{pmol} / \mu \mathrm{l}$ reverse primer $\left(5^{\prime}\right.$-TCCATCGCTTA CATCTTACCA- $3^{\prime}$ ), and $2.5 \mathrm{U}$ of AmpliTaq DNA polymerase in a $20 \mu \mathrm{l}$ reaction. PCR cycles were $94^{\circ} \mathrm{C}$ for $5 \mathrm{~min}$, followed by 30 cycles of $94^{\circ} \mathrm{C}$ for $30 \mathrm{~s}, 58^{\circ} \mathrm{C}$ for $30 \mathrm{~s}, 72^{\circ} \mathrm{C}$ for $1 \mathrm{~min}$, followed by a final extension step of $72^{\circ} \mathrm{C}$ for $5 \mathrm{~min}$. A Ginsertion in exon 10 of the B6 Oprm gene (data not shown) creates a DdeI restriction site. When the $403 \mathrm{bp}$ amplicon from B6 is digested with DdeI, it creates two bands of 235 and $168 \mathrm{bp}$. For genotype analysis, $10 \mu \mathrm{l}$ of the reaction was digested with the DdeI restriction enzyme (New England Biolabs, Beverly, MA) following the manufacturer's recommended conditions. Products were run on a 5\% nondenaturing polyacrylamide gel and stained with ethidium bromide.

\section{Morphine Consumption}

Morphine consumption and preference were quantified using a two-bottle choice paradigm as described previously (Berrettini et al, 1994b). Briefly, mice (male, 8-12 weeks of age) were housed individually in cages with two water bottles for 1 week prior to the start of the 12-day test paradigm. On days $1-4$ of the test, both drinking bottles contained water. Fluid intake was measured by weighing the bottles between 0900 and 1000 daily. On days 5-8, the water in one bottle was replaced with a solution of morphine sulfate $(0.4 \mathrm{mg} / \mathrm{ml})$ in $0.2 \%$ saccharin and the water in the other (control) bottle was replaced with a solution of 
quinine $(0.2 \mathrm{mg} / \mathrm{ml})$ in $0.2 \%$ saccharin. Mice were allowed continuous access to both bottles. To minimize effects related to learning, the position of the bottles in the cage was alternated at the time of daily bottle weighing. On days $9-12$, the concentration of morphine was increased to $0.7 \mathrm{mg} / \mathrm{ml}$ and the concentration of quinine was increased to $0.4 \mathrm{mg} / \mathrm{ml}$. Again mice were allowed continuous access. Body weights of the mice were measured every other day throughout the test paradigm. We also used a modified version of the test in which quinine was eliminated from the control bottle while all other parameters were maintained as described above.

\section{Data Analysis}

The study was conducted in three parts. In the first part, six mice from each of the four strains (B6, D2, B6.D2-Mop2, and D2.B6-Mop2) were tested simultaneously in the twobottle choice paradigm with morphine and quinine. In the second part, which took place approximately 8 weeks after the first, the same protocol was repeated using naïve mice. Strain data from the two experiments were first compared by $t$-test and, with no significant differences noted, were then combined for further analysis. In the third part, additional mice from each of the four strains $(n=4$ per strain) were tested in the paradigm without quinine. Daily drinking values were entered into a Microsoft Excel workbook and statistical analyses were conducted with the DOS-based Truepistat software package (Truepistat, Richardson, TX). One-way ANOVA was used to evaluate the influence of genetic background on morphine, quinine and saccharin consumption $(\mathrm{mg} / \mathrm{kg} /$ day) and also on morphine preference (percent of total fluid intake). Analyses were based on drinking values for each mouse averaged over the last 4 days (days 9-12) of the two-bottle test paradigm. Between-group comparisons were conducted post hoc with the Neuman-Keuls test. Total fluid intake measures were analyzed by comparing the average daily value over days 1-4 with the average daily value over days 9-12 for each strain using a two-way ANOVA and Neuman-Keuls post hoc test.

\section{RESULTS}

Data shown in Figure 2 confirm the large difference between B6 and D2 mice with respect to oral morphine intake in the two-bottle choice paradigm. In this study, B6 mice consumed about $150 \mathrm{mg} / \mathrm{kg} /$ day on average, whereas D2 mice consumed about $20 \mathrm{mg} / \mathrm{kg} /$ day. As predicted from mapping studies (Berrettini et al, 1994b), B6.D2-Mop2 mice exhibited significantly reduced morphine consumption compared to parental B6 mice with about one-half of total morphine consumption in B6 mice explained by the Mop2 locus on chromosome 10. Also in keeping with the prediction, D2.B6-Mop2 mice consumed significantly more morphine (about four-fold) than progenitor D2 mice, demonstrating the large effect of the B6 Mop2 locus when isolated on a D2 genetic background. This locus seems to function in a dominant or semidominant mode since effects of similar magnitude were observed in heterozygous congenic mice at generations N4 and N7 (data not shown). With respect to quinine, D2 mice consumed over two times

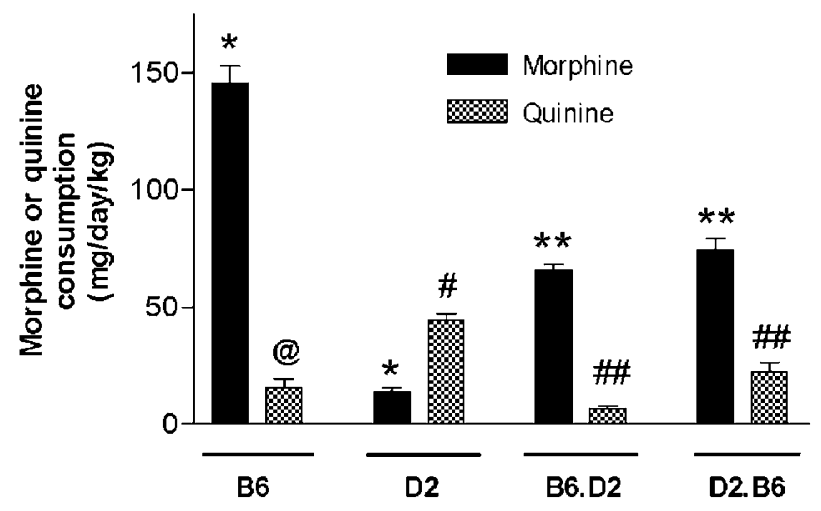

Figure 2 Morphine and quinine consumption in parental and Mop2 congenic strains. Mice were tested in the two-bottle choice paradigm with morphine plus saccharin vs quinine plus saccharin as described in Methods. The top of each bar represents the mean ( + SEM) consumption over days 9-12 $(n=12) . * P<0.01$ vs all other morphine groups; $* * *<0.01$ vs $B 6$ and D2 morphine; ${ }^{\#} P<0.0$ I vs all other quinine groups; ${ }^{\# \#} P<0.0$ I vs D2 and reciprocal congenic strains; ${ }^{@} P<0.01$ vs D2 quinine.

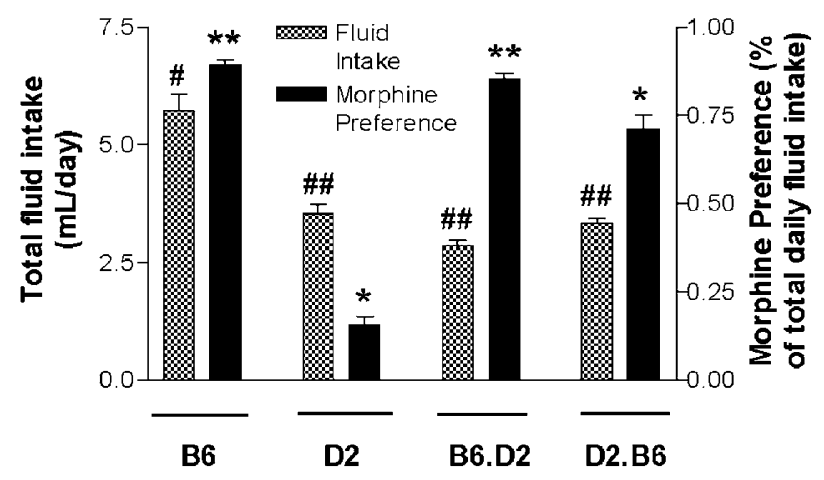

Figure 3 Morphine preference and total fluid intake in parental and Mop2 congenic strains. Mice were tested in the two-bottle choice paradigm with morphine plus saccharin vs quinine plus saccharin as described in Methods. The top of each bar represents the mean ( + SEM) preference or intake value over days $9-12(n=12)$. $* P<0.01$ vs all other group preferences; ${ }^{*} * P<0.01$ vs D2 and D2.B6 preference; ${ }^{*} P<0.01$ vs all other total fluid intake values; ${ }^{\#} p<0.01$ vs B6 total fluid intake.

more than $\mathrm{B} 6$ mice, an effect that was partially abrogated in D2.B6-Mop2 mice, as the latter exhibited increased morphine consumption relative to D2 in association with decreased quinine consumption. On the other hand, there was no significant change in quinine consumption in B6.D2-Mop2 mice compared to B6 mice in spite of a significant reduction in morphine consumption.

When drinking data were expressed as preference scores, a slightly different picture emerged (Figure 3). Compared to preference scores for B6 mice, which were greater than 0.9 ( $90 \%$ of daily fluid from the morphine bottle), scores in B6.D2-Mop2 congenic mice were not significantly different. Related to this finding, it is noteworthy that total fluid consumption increased by about $50 \%$ in B6 mice specifically during the morphine/quinine phase of the two-bottle choice test (days 5-12). Thus, during days $1-4$ of the test, when both bottles contained water, all four strains drank the same amount of daily fluid, about $4 \mathrm{ml}$ (data not shown). This value increased to about $6 \mathrm{ml} /$ day in $\mathrm{B} 6$ mice during 


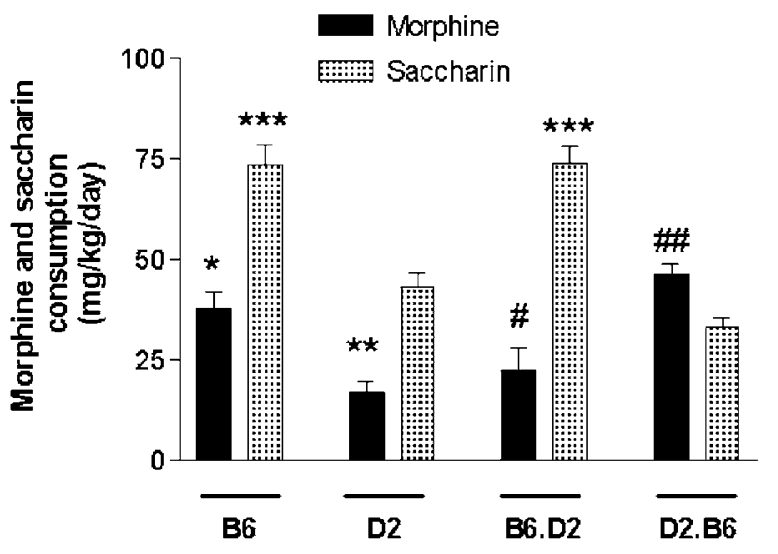

Figure 4 Morphine and saccharin consumption in parental and Mop2 congenic strains. Mice were tested in the two-bottle choice paradigm with morphine plus saccharin vs saccharin as described in Methods. The top of each bar represents the mean ( + SEM) consumption over days 9-12 $(n=4)$. ${ }^{*} P<0.01$ vs D2, 0.05 vs B6.D2; ${ }^{*} * P<0.01$ vs B6, D2.B6; ${ }^{\#} P<0.01$ vs D2.B6, 0.05 vs B6; ${ }^{\#} P<0.01$ vs D2, B6.D2; ${ }^{*} * * * P<0.01$ vs D2, D2.B6.

days 5-12 $(P<0.01$ vs days $1-4)$, whereas the other strains showed slight decreases that were not statistically significant compared to intake on days 1-4. Lack of decrease in preference score of B6.D2-Mop2 congenic mice relative to B6 mice in spite of a $50 \%$ reduction in morphine consumption reflects this difference in total fluid consumption. On the other hand, preference scores for D2.B6-Mop2 mice were significantly increased (about four-fold) compared to scores for D2 mice, which were about 0.15 with similar levels of total fluid intake.

Elimination of quinine from the control bottle had several effects on drinking behavior. Most notably, morphine intake decreased in all strains due to the natural preference of mice for sweet tasting substances (Figure 4). In spite of the fact that B6 mice exhibited a sharp reduction in morphine intake (levels were reduced to about one-third of those observed when quinine was included) and also significantly greater saccharin intake than D2 mice, morphine intake was still significantly greater than that exhibited by both D2 and B6.D2-Mop2 mice (Figure 4). Furthermore, the level of morphine intake was significantly lower in D2 compared to D2.B6-Mop2. With regard to morphine preference, although omission of quinine decreased slightly the high preference level exhibited by D2.B6-Mop2 mice, this level was significantly greater than that exhibited by B6 mice (Figure 5). On the other hand, morphine preference level for B6.D2-Mop2 mice was decreased significantly relative to $\mathrm{B} 6$ mice. This latter result stands in sharp contrast to that obtained when quinine was included in the drinking paradigm.

\section{DISCUSSION}

The robust difference between B6 and D2 mice in voluntary morphine self-administration by the oral route was proposed several decades ago as a genetic model of opioid addiction (Horowitz et al, 1977). Since then, a number of laboratories have pursued studies of this mouse model. Confirmation of the strain difference between B6 and D2

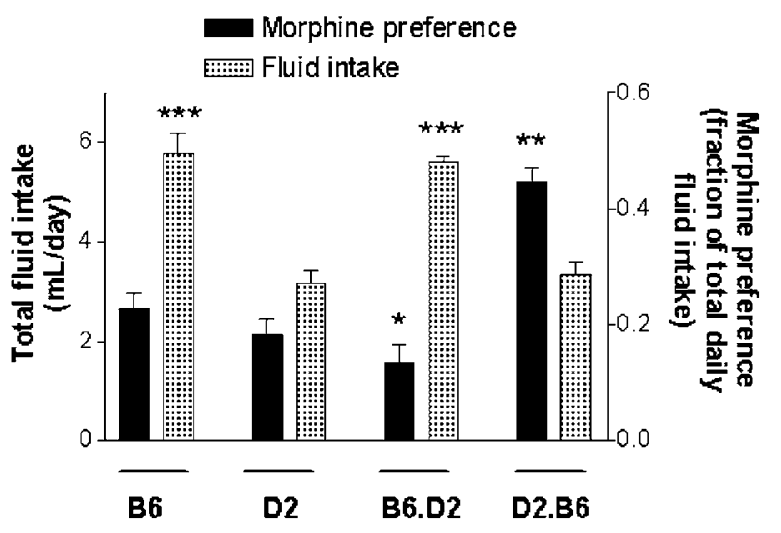

Figure 5 Morphine preference and total fluid intake in parental and Mop2 congenic strains. Mice were tested in the two-bottle choice paradigm with morphine plus saccharin vs saccharin as described in Methods. The top of each bar represents the mean ( + SEM) preference or intake value over days $9-12(n=4)$. ${ }^{*} P<0.0$ I vs D2.B6, 0.05 vs B6; ** $P<0.01$ vs all other groups; **** $P<0.0$ I vs D2, D2.B6.

mice in oral morphine preference (Belknap, 1990; Belknap et al, 1993) was followed by a quantitative genetic study that mapped a major locus for the trait to chromosome 10 (Berrettini et al, 1994b). This QTL for oral morphine preference, termed Mop2, was confirmed in a follow-up study (Alexander et al, 1996) and support was generated for the concept that it had a broader influence with regard to the pharmacological effects of morphine being involved also in determining morphine-induced analgesia and the density of $\left[{ }^{3} \mathrm{H}\right]$ naloxone binding sites in the brain (Belknap et al, 1995). Subsequent mapping of the $M u$ opioid receptor gene (Oprm) to the same chromosomal location as the Mop2 QTL (Kozak et al, 1994; Giros et al, 1995) focused attention on this gene as a strong candidate for mediating differences in opioid-related effects between B6 and D2 mice. In spite of intensive study, the causative genetic variation that underlies Mop2 has yet to be identified. Oprm knockout mice on the B6 genetic background exhibit lack of morphineinduced analgesia, locomotor activity, and conditioned place preference (Hall et al, 2003). Oprm knockout mice have also been shown to lack robust responsiveness in intracerebroventricular morphine self-administration studies (Becker et al, 2000); however, this latter study did not control for genetic background and did not test responsiveness of knockout mice in a voluntary drinking paradigm. Thus, the role of Oprm and the $M u$ opioid receptor in mediating the differential effects of morphine in B6 and D2 mice is still unresolved.

The present study was carried out to map Mop2 to a defined genomic interval and also to isolate it for further characterization. The results of experiments with reciprocal congenic strains reported here confirm that a gene(s) with a large effect on oral morphine consumption and preference lies between the centromere (acromere) and D10Mit124 on chromosome 10. This conclusion is supported by data generated using the D2.B6-Mop2 strain in which both morphine consumption and preference were increased relative to the D2 background strain. On the other hand, comparison of the results between B6.D2-Mop2 and B6 mice supports the existence of a gene that influences morphine 
consumption on proximal chromosome 10 , but not one that influences preference. Given the difference in the size of the introgressed interval between the two reciprocal congenic strains (Figure 1), it is possible that the 'preference gene(s)' is distinct from the 'consumption gene(s)' and is located between D10Mit124 and D10Mit186. A more likely explanation for high morphine preference in B6.D2-Mop2 mice relative to progenitor B6 mice involves taste effects associated with quinine in the control bottle. Morphine consumption depends on the rewarding properties of the drug; however, preference is influenced by the degree of quinine aversion. Thus, it is possible that aversion to the bitter taste of quinine results in maintenance of relatively high levels of fluid consumption from the morphine bottle in spite of a presumed reduction in the rewarding effect of the drug. This interpretation is supported by the results of the experiment in which quinine was omitted from the control bottle. Under this condition, not only did the chromosome 10 region of introgression influence morphine intake in a reciprocal manner, but it also influenced preference similarly. This interpretation is also supported by mapping results in which preference scores in the morphine/quinine two-bottle choice paradigm were shown to be influenced strongly by a locus on chromosome 6 (Berrettini et al, 1994b; Lush, 1984).

In summary, we have created a reciprocal pair of congenic mouse strains to confirm the existence of the Mop2 QTL on chromosome 10. The results indicate that Mop2 is located proximal to D10Mit124 and that it is a major determinant of the difference in both morphine consumption and morphine preference between B6 and D2 mice. Further reduction of the Mop 2 critical interval may be achieved using a strategy that involves identifying recombinant progeny and propagating new interval specific congenic strains for behavioral testing. This systematic approach to dissecting the Mop2 critical interval may lead to the identification of the causative genetic variation that underlies significant differences in the pharmacology of opioids between B6 and D2 mice.

\section{ACKNOWLEDGEMENTS}

We thank Dr Alexander Bachmanov for helpful discussion. This work was supported by NIH Grant DA14008.

\section{REFERENCES}

Abiola O, Angel JM, Avner P, Bachmanov AA, Belknap JK, Bennett $\mathrm{B}$, et al, Complex Trait Consortium (2003). The nature and identification of quantitative trait loci: a community's view. Nat Rev Genet 4: 911-916.

Alexander RC, Heydt D, Ferraro TN, Vogel W, Berrettini WH (1996). Further evidence for a quantitative trait locus on murine chromosome 10 controlling morphine preference in inbred mice. Psychiatric Genet 6: 29-31.

Becker A, Grecksch G, Brodemann R, Kraus J, Peters B, Schroeder $\mathrm{H}$ et al (2000). Morphine self-administration in mu-opioid receptor-deficient mice. Naunyn Schmiedebergs Arch Pharmacol 361: 584-589.

Belknap JK (1990). Physical dependence induced by the voluantary consumption of morphine in inbred mice. Pharmacol Biochem Behav 35: 311-315.

Belknap JK, Crabbe JC, Riggan J, O’Toole LA (1993). Voluntary consumption of morphine in 15 inbred mouse strains. Psychopharmacology 112: 352-358.

Belknap JK, Mogil JS, Helms ML, Richards SP, O'Toole LA, Bergeson SE et al (1995). Localization to chromosome10 of a locus influencing morphine analgesia in crosses derived from C57BL/6 and DBA/2 strains. Life Sci 57: PL117-PL124.

Bennett B, Beeson M, Gordon L, Johnson TE (2002). Reciprocal congenics defining individual quantitative trait loci for sedative/ hypnotic sensitivity to ethanol. Alcohol Clin Exp Res 26: 149-157.

Berrettini WH, Alexander R, Ferraro TN, Vogel WH (1994a). A study of oral morphine preference in inbred mouse strains. Psychiatric Genet 4: 81-86.

Berrettini WH, Ferraro TN, Alexander RC, Buchberg AM, Vogel WH (1994b). Quantitative trait loci mapping of three loci controlling morphine preference using inbred mouse strains. Nat Genet 7: 54-58.

Ferraro TN, Golden GT, Smith GG, Martin JF, Lohoff FW, Gieringer TA et al (2004). Fine mapping of a seizure susceptibility locus on mouse chromosome 1: nomination of Kcnj10 as a causative gene. Mamm Genome 15: 239-251.

Ferraro TN, Schill JF, Ballas C, Mulholland N, Golden GT, Smith GG et al (1998). Genotyping microsatellite polymorphisms by agarose gel electrophoresis with ethidium bromide staining: application to quantitative trait loci analysis of seizure susceptibility in mice. Psychiatric Genet 8: 227-233.

Flaherty L (1981). Congenic strains. In: Foster HL, Small JD, Fox JG (eds). The Mouse in Biomedical Research, Vol. 1. New York: Academic Press, pp 215-222.

Giros B, Pohl M, Rochelle JM, Seldin MF (1995). Chromosomal localization of opioid peptide and receptor genes in the mouse. Life Sci 56: PL369-PL375.

Hall FS, Li XF, Goeb M, Roff S, Hoggatt H, Sora I et al (2003). Congenic C57BL/6 mu opiate receptor (MOR) knockout mice: baseline and opiate effects. Genes Brain Behav 2: 114-121.

Horowitz GP, Whitney G, Smith JC, Stephan FK (1977). Morphine ingestion: genetic control in mice. Psychopharmacology 29: 119-122.

Kozak CA, Filie J, Adamson MC, Chen Y, Yu L (1994). Murine chromosomal location of the mu and kappa opioid receptor genes. Genomics 21: 659-661.

Legare ME, Bartlett FS, Frankel WN (2000). A major effect QTL determined by multiple genes in epileptic EL mice. Genome Res 10: $42-48$.

Legare ME, Frankel WN (2000). Multiple seizure susceptibility genes on chromosome 7 in SWXL-4 congenic mouse strains. Genomics 70: 62-65.

Lush IE (1984). The genetics of tasting in mice. III. Quinine. Genet Res 44: 151-160. 